\title{
Early and Long-Term Outcomes of Venous Stent Implantation for Iliac Venous Stenosis After Catheter-Directed Thrombolysis for Acute Deep Vein Thrombosis
}

\author{
Akimasa Matsuda, MD; Norikazu Yamada, MD, PhD; Yoshito Ogihara, MD; \\ Akihiro Tsuji, MD, PhD; Satoshi Ota, MD, PhD; Ken Ishikura, MD, PhD; \\ Mashio Nakamura, MD, PhD; Masaaki Ito, MD, PhD
}

\begin{abstract}
Background: Although stent implantation is used worldwide for peripheral arterial disease, there is little data on the safety and long-term patency of stents implanted for venous disease.
\end{abstract}

Methods and Results: We studied 13 patients with 14 lesions (6 males, 7 females, mean age: $63.2 \pm 10.2$ years) diagnosed with venous stenosis and who underwent venous stenting. We examined the location of the stenosis, safety of venous stenting, implantation success rate, and long-term stent patency rate. All patients were suffering from venous stenosis in the left common iliac vein because of iliac vein compression syndrome. No major complications occurred during stent implantation. Acute stent occlusion occurred in 1 patient, who was given additional thrombolytic therapy. Of the 13 patients, 10 underwent venography or contrast-enhanced computed tomography (CT) during mid-term followup (mean: $12.9 \pm 16.1$ months), and only 1 stent was occluded, resulting in a patency rate of $90.0 \%$. The latter patient decided to stop taking warfarin soon after stent implantation. Furthermore, 5 patients underwent contrast-enhanced CT to assess the long-term patency of their stents (mean: 79.6 \pm 31.2 months), and none was occluded.

Conclusions: Venous stents display a high long-term patency rate, and hence are a useful tool for treating iliac venous stenosis. (Circ J 2014; 78: 1234-1239)

Key Words: Deep vein thrombosis; Iliac vein compression syndrome; Venous stenosis; Venous stents

$\mathbf{T}$ reatments for deep vein thrombosis (DVT) aim to prevent thrombus extension, pulmonary thromboembolism, and the long-term complications of post-thrombotic syndrome including persistent leg pain, chronic leg swelling, hyperpigmentation, and skin ulceration. Early thrombolysis seems to be important for preserving venous valvular function. Although stent implantation is used to treat peripheral arterial obstruction or stenosis worldwide,,$^{1,2}$ there is little data on the efficacy and long-term patency of stents that are implanted for venous disease. We perform catheter-directed thrombolysis for acute iliofemoral DVT, but we have often experienced recurrence soon after successful thrombolysis despite administration of anticoagulation therapy within the therapeutic range. Residual venous outflow obstruction or stenosis after clot lysis can lead to venous thrombus formation because of venous stasis and/or endothelial injury. The most common cause of outflow obstruction or stenosis is extrinsic compression of the iliac vein [eg, May-Thurner or Cockett's syndrome (in which the left common iliac vein is compressed between the right common iliac artery and the spine)]. We perform venous stent implantation in cases of severe stenosis associated with blood stagnation or symptomatic venous return disorders because of venous stenosis. In this study, we examined the short- and long-term efficacy and safety of venous stent implantation for iliac venous stenosis.

\section{Editorial $\mathrm{p} 1069$}

\section{Methods}

Patient Selection and Evaluation

The subjects were 13 patients who continued to exhibit leg swelling and pain from severe venous stenosis or significant venous stasis, which was detected by venography through the

Received October 10, 2013; revised manuscript received January 6, 2014; accepted January 21, 2014; released online March 3, 2014 Time for primary review: 33 days

Department of Cardiology and Nephrology (A.M., N.Y., Y.O., S.O., K.I., M.I.), Clinical Cardiovascular Research (M.N.), Mie University Graduate School of Medicine, Mie; and National Cerebral and Cardiovascular Center, Osaka (A.T.), Japan

Mailing address: Norikazu Yamada, MD, PhD, Department of Cardiology and Nephrology, Mie University Graduate School of Medicine, 2-174, Edobashi, Tsu 514-8507, Japan. E-mail: n-yamada@clin.medic.mie-u.ac.jp

ISSN-1346-9843 doi:10.1253/circj.CJ-13-1247

All rights are reserved to the Japanese Circulation Society. For permissions, please e-mail: cj@j-circ.or.jp 


\begin{tabular}{|c|c|c|c|c|c|c|}
\hline Case no. & Age (years) & Sex & Risk factors & Location of DVT & Stenotic lesion & Cause \\
\hline 1 & 66 & $\mathrm{~F}$ & Orthopedic surgery & CIV-PV & Left CIV & IC \\
\hline 2 & 64 & M & Protein S deficiency, left hemiplegia & CIV-PV & Left CIV & IC \\
\hline 3 & 72 & M & None & EIV-PV & Left CIV & IC \\
\hline 4 & 51 & $\mathrm{~F}$ & Orthopedic surgery & CIV-PV & Left CIV & IC \\
\hline 5 & 71 & $\mathrm{~F}$ & Abdominal surgery & CIV-CFV & Left CIV & IC \\
\hline 6 & 70 & $\mathrm{~F}$ & Carcinoma of the breast & CIV-PV & $\begin{array}{l}\text { Left CIV } \\
\text { Left EIV }\end{array}$ & $\begin{array}{l}\text { IC } \\
\text { OT }\end{array}$ \\
\hline 7 & 43 & M & Antithrombin deficiency, amyotrophic lateral sclerosis & CIV-PV & Left CIV & IC \\
\hline 8 & 65 & M & $\begin{array}{l}\text { Paralysis of the lower part of the body; postoperative } \\
\text { gastric carcinoma }\end{array}$ & CIV-PV & Left CIV & IC \\
\hline 9 & 69 & $\mathrm{~F}$ & Carcinoma of the cervix (after radiotherapy) & EIV-PV & Left CIV & IC \\
\hline 10 & 75 & M & Obesity & EIV-PV & Left CIV & IC \\
\hline 11 & 57 & $\mathrm{~F}$ & Orthopedic surgery & CIV-PV & Left CIV & IC \\
\hline 12 & 70 & $\mathrm{~F}$ & Lumbar compression fracture & CIV-PV & Left CIV & IC \\
\hline 13 & 48 & M & Antipsychotic drug use; postoperative testicular tumor & EIV-SFV & Left CIV & IC \\
\hline
\end{tabular}

CFV, common femoral vein; CIV, common iliac vein; DVT, deep vein thrombosis; EIV, external iliac vein; IC, iliac compression; OT, organized thrombus; PTS, post-thrombotic syndrome; PV, popliteal vein; SFV,superficial femoral vein.

popliteal sheath, after catheter-directed thrombolytic therapy and/or rheolytic thrombectomy for acute DVT.

All 13 patients underwent venous stent implantation between May 2000 and June 2008. The following information was obtained for each case: intravascular ultrasound (IVUS) scan findings; the number, size, and type of stents used; the stent implantation site; and whether thrombolysis or concurrent inferior vena cava (IVC) filter was used. In addition, complications that occurred after stent implantation, including recurrent venous thromboembolism, post-thrombotic syndrome, and stent fracturing, were recorded. The length of the follow-up period was determined by the timing of the last imaging examination of the stent.

\section{Procedure}

After implanting a retrievable IVC filter (Günther Tulip ${ }^{\mathrm{TM}}$ Vena Cava Filter Retrieval Set; Cook Medical, Bloomington, IN, USA) from the right internal jugular vein, we placed a sheath in the popliteal vein ipsilateral to the lesion and performed venography. In all patients, we performed catheter-directed thrombolysis (Fountain ${ }^{\circledR}$ Infusion System; Merit Medical, South Jordan, UT, USA). We also performed rheolytic thrombectomy in 4 of the patients, ${ }^{3}$ using the 8 Fr Oasis Thrombectomy System (Boston Scientific, Natick, MA, USA) as the rheolytic device.

If patients had venous stasis because of severe stenosis after complete thrombolysis, we implanted a venous stent. We excluded young subjects aged less than 40 years because the longterm safety after venous stent implantation has not yet been established. Also, we excluded patients with a rich collateral through the pelvic venous plexus even if there was iliac vein compression syndrome. Furthermore, we excluded patients with a larger vessel diameter $(>12 \mathrm{~mm})$ than the size of available stents in Japan.

The length of the stent was chosen based on the length of the stenotic lesion on venography, and we chose the stent diameter based on measurements of venous diameter on IVUS. After the stent had been implanted, its expansion was confirmed by IVUS. Patients who exhibited inadequate stent expansion were treated with low-pressure balloon dilatation.

After stent implantation, we attempted to retrieve the IVC filter after cavography or contrast-enhanced computed tomog- raphy (CT) detected no thrombus trapped in the IVC filter.

During the procedure, all patients underwent full anticoagulation with unfractionated heparin through the side port of the introducer sheath. The heparin dose was adjusted to produce an activated partial thromboplastin time of twice the control value. After the procedure, all the patients were started on additional warfarin. The unfractionated heparin was discontinued after a therapeutic prothrombin time-international normalized ratio (PT-INR) had been obtained. The warfarin dose was adjusted to produce a PT-INR of 1.5-2.5.

\section{Follow-up}

Acute stent patency (within 2 weeks of stent implantation) and mid-term stent patency (approximately 1 year after stent implantation) were assessed with venography or contrast-enhanced CT; 3 patients were lost to mid-term follow-up, and we evaluated long-term stent patency ( $>3$ years later) with contrast-enhanced CT in 5 patients.

We diagnosed post-thrombotic syndrome based on the CEAP classification. ${ }^{4}$

\section{Results}

The characteristics of the 13 patients ( 6 males, 7 females; mean age $63.2 \pm 10.2$ years) enrolled in this study are shown in Table 1. During the same period, there were 74 cases of DVT for which catheter-directed thrombolysis was performed in our hospital, and the stent implantation rate was $17.6 \%$. All patients were suffering from acute DVT or venous stenosis in the left common iliac vein because of iliac vein compression syndrome and continued to exhibit symptoms such as leg swelling and pain or venous stasis related to venous stenosis after thrombolytic therapy. One patient had stenotic lesions in both the left common iliac and external iliac vein. Thrombophilia, including protein $\mathrm{S}$ deficiency and antithrombin deficiency, was detected in 2 patients.

\section{Stents}

The stent implantation sites were the left common iliac vein in 13 lesions and the left external iliac vein in 1 lesion. Easy Wallstents (Boston Scientific) were implanted into 7 patients, SMART stents (Cordis, Bridgewater, NJ, USA) were implant- 


\begin{tabular}{|c|c|c|c|c|c|c|}
\hline Case no. & Stent & Diameter $(\mathrm{mm})$ & Length (mm) & Predilatation & Post-dilatation & $\begin{array}{l}\text { Additional thrombolytic } \\
\text { therapy after stenting }\end{array}$ \\
\hline 1 & Easy Wallstent & 10 & 50 & - & - & - \\
\hline 2 & Easy Wallstent & 12 & 50 & + & - & - \\
\hline 3 & Easy Wallstent & 10 & 65 & + & - & - \\
\hline 4 & SMART & 12 & 60 & + & - & - \\
\hline 5 & SMART & 12 & 40 & + & + & + \\
\hline \multirow[t]{2}{*}{6} & SMART & 10 & 60 & + & + & + \\
\hline & SMART & 10 & 40 & + & - & + \\
\hline 7 & Easy Wallstent & 12 & 50 & + & + & + \\
\hline 8 & Easy Wallstent & 10 & 65 & + & + & + \\
\hline 9 & Luminexx & 10 & 100 & + & - & - \\
\hline 10 & Easy Wallstent & 12 & 50 & + & + & - \\
\hline 11 & Easy Wallstent & 12 & 30 & + & + & - \\
\hline 12 & SMART & 10 & 40 & + & + & - \\
\hline 13 & SMART & 10 & 40 & + & + & - \\
\hline
\end{tabular}

\begin{tabular}{|c|c|c|c|c|c|c|}
\hline Case no. & $\begin{array}{l}\text { Occlusion in } \\
\text { acute phase }\end{array}$ & $\begin{array}{c}\text { Occlusion in } \\
\text { mid-term phase }\end{array}$ & $\begin{array}{l}\text { Diagnostic } \\
\text { method }\end{array}$ & $\begin{array}{l}\text { Warfarin therapy } \\
\text { (duration) }\end{array}$ & $\begin{array}{l}\text { Recurrence } \\
\text { of VTE }\end{array}$ & Prognosis \\
\hline 1 & $(-)$ & $(-)$ & Venography & Discontinued (84 months) & & Died of tongue cancer \\
\hline 2 & $(+)$ & $(-)$ & Venography & Continuing & $(-)$ & \\
\hline 3 & $(-)$ & Not examined & $(-)$ & Discontinued (48 months) & $(-)$ & \\
\hline 4 & $(-)$ & $(-)$ & Venography & Discontinued (51 months) & $(-)$ & \\
\hline 5 & $(-)$ & $(-)$ & Venography & Discontinued (45 months) & $(-)$ & \\
\hline 6 & $(-)$ & $(-)$ & Venography & Continuing & $(-)$ & \\
\hline 7 & $(-)$ & $(-)$ & Enhanced CT & Continuing & $(-)$ & \\
\hline 8 & $(-)$ & $(-)$ & Venography & Continuing & & Died of postoperative ileus \\
\hline 9 & $(-)$ & $(+)$ & Enhanced CT & Discontinued (28 months) & $(-)$ & \\
\hline 10 & $(-)$ & not examined & $(-)$ & Discontinued (32 months) & $(-)$ & \\
\hline 11 & $(-)$ & not examined & $(-)$ & Discontinued (6 months) & $(-)$ & \\
\hline 12 & $(-)$ & $(-)$ & Enhanced CT & Continuing & $(-)$ & \\
\hline 13 & $(-)$ & $(-)$ & Enhanced CT & Continuing & $(-)$ & \\
\hline
\end{tabular}

VTE, venous thromboembolism.

ed into 5 patients, and a Luminexx stent (Bard Medical, Covington, GA, USA) was implanted into 1 patient (Table 2). The mean stent diameter was $10.9 \pm 1.0 \mathrm{~m}$, and the mean stent length was $52.9 \pm 17.2 \mathrm{~mm}$.

\section{Balloon Venoplasty for Pre- and Post-Stent Implantation Dilatation}

All the patients underwent balloon venoplasty to induce venous dilatation prior to stent implantation. In addition, we performed balloon venoplasty for post-stent implantation dilatation in 8 patients. In addition, thrombolytic therapy for residual thrombi was administered after stent implantation in 5 patients. Of them, the residual thrombi were located outside of the stent in 4 patients, and within the stent in 1 patient (Table 2).

\section{Acute Phase Results}

Acute stent patency (within 2 weeks of stent implantation, mean follow-up period: $5.7 \pm 3.7$ days) was assessed with venography (11 patients) or contrast-enhanced CT ( 2 patients). During the acute phase follow-up period, 1 patient suffered complete occlusion caused by a thrombus (Figure 1). Hence, the stent patency rate during the acute phase was $92.3 \%$ (Table 4).

\section{Complications Related to Stent Implantation}

No major complications occurred during stent implantation; 1 patient exhibited in-stent thrombosis immediately after stent implantation. There were no complications such as pulmonary thromboembolism, vascular injury, major bleeding, stent fracturing, or stent migration.

\section{Retrieval of the IVC Filters}

All the IVC filters that had been implanted in the patients with acute DVT were successfully retrieved after thrombolysis and stent implantation. No complications related to IVC filter implantation or retrieval occurred.

\section{Mid-Term Follow-up}

We administered warfarin-based anticoagulation therapy to all patients; 3 patients were lost to the mid-term follow-up; 1 patient suffered leg swelling because of a stent occlusion during the mid-term follow-up period (mean follow-up period: 12.9 \pm 16.1 months). Imaging studies (venography: 6 patients, contrast-enhanced CT: 4 patients) were performed for the remaining 10 patients to verify whether the stents were occluded, but stent occlusion was only detected in 1 patient. Thus, the stent patency rate for the mid-term phase was $90.0 \%$. 


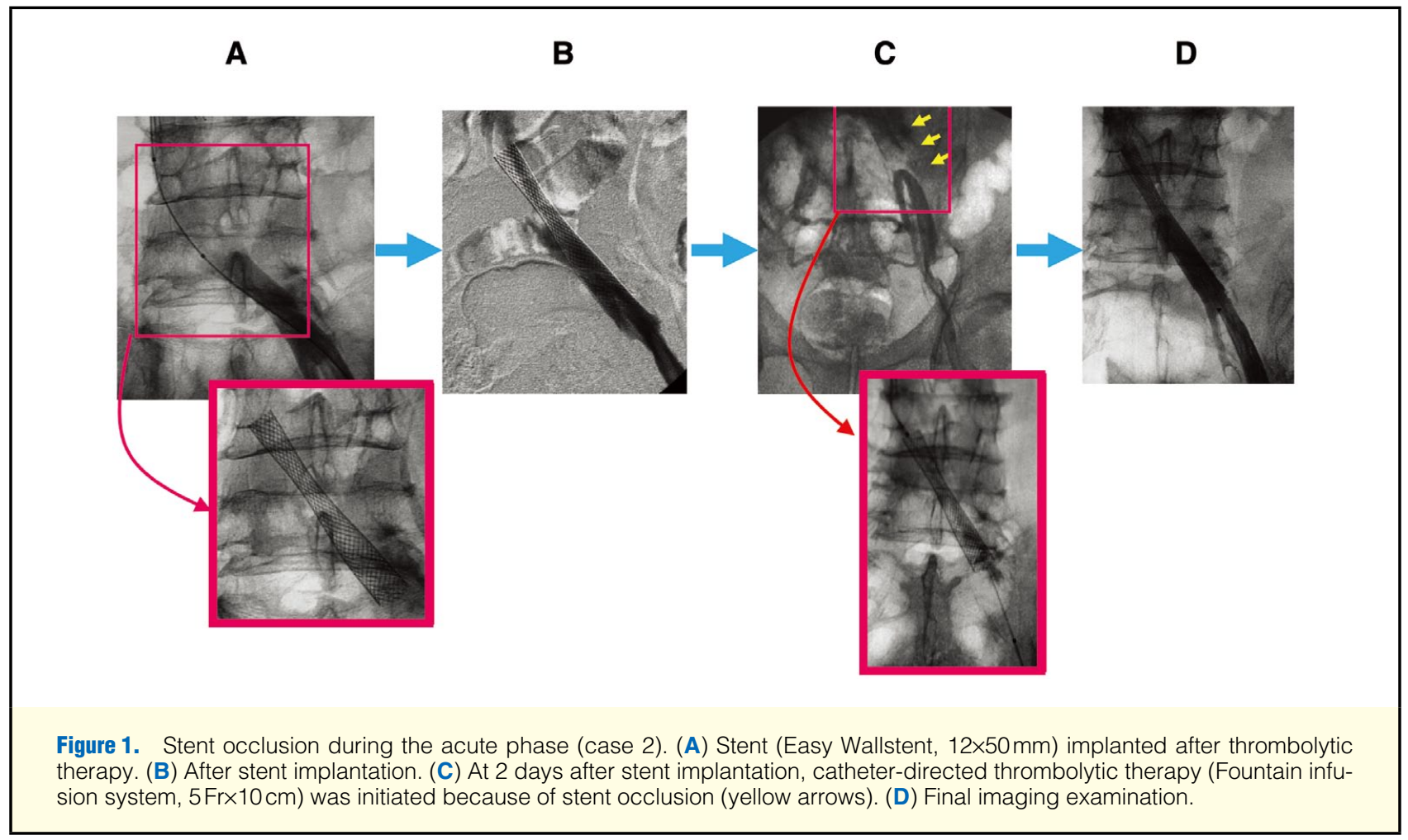

\begin{tabular}{|c|c|c|c|c|c|c|}
\hline Year & Author & $\mathbf{n}$ & $\begin{array}{c}\text { Acute phase } \\
\text { patency rate (\%) }\end{array}$ & $\begin{array}{l}\text { Chronic phase } \\
\text { patency rate (\%) }\end{array}$ & $\begin{array}{l}\text { Follow-up } \\
\text { (months) }\end{array}$ & $\begin{array}{l}\text { Diagnostic } \\
\text { method }\end{array}$ \\
\hline 1998 & Binkert et $\mathrm{al}^{13}$ & 8 & 100 & 100 & 35 & $\begin{array}{l}\text { Venous US } \\
\text { Venography }\end{array}$ \\
\hline 2000 & Patel et al ${ }^{14}$ & 10 & 100 & 80 & 36 & Venous US \\
\hline 2000 & O'Sullivan et al ${ }^{15}$ & 35 & 93.6 & 93.6 & 12 & Venous US \\
\hline 2001 & Heijmen et al ${ }^{16}$ & 6 & 100 & 83 & 12 & Venous US \\
\hline 2001 & Hurst et a $\left.\right|^{17}$ & 17 & - & 79 & $14 \sim 17$ & $\begin{array}{l}\text { Venography } \\
\text { Venous US }\end{array}$ \\
\hline 2002 & Lamont et al ${ }^{18}$ & 15 & 93 & 87 & 16 & Venous US \\
\hline 2005 & Kwak et al ${ }^{19}$ & 22 & 96 & 95 & 24 & Venous US \\
\hline 2006 & Kim et $\mathrm{al}^{20}$ & 18 & 100 & 88 & 6 & Venography \\
\hline 2008 & Hartung et $\mathrm{al}^{21}$ & 29 & 89.7 & 78.9 & 63 & Venous US \\
\hline \multirow[t]{3}{*}{2012} & Funatsu and Nakamura 22 & 20 & 95 & 93.8 & 50 & $\begin{array}{l}\text { Venography } \\
\text { Venous US }\end{array}$ \\
\hline & & & mean: 96 & mean: 88 & & \\
\hline & Present study & 13 & 92.3 & 90.0 & 79.9 & $\begin{array}{l}\text { Venography } \\
\text { Enhanced CT }\end{array}$ \\
\hline
\end{tabular}

\section{Representative Case of Stent Occlusion}

A 69-year-old woman (case no. 9) was admitted because of acute proximal DVT, and catheter-directed thrombolysis was initiated. After the clot had been dissolved, we implanted a stent (Luminexx, 10×100 mm) in a severe stenotic lesion in her left common iliac vein, which had been caused by iliac compression syndrome. After stent implantation, adequate stent expansion was confirmed by venography and IVUS. After discharge, the patient stopped taking warfarin of her own accord (10 days after stenting); however, her left leg subsequently began to swell. Complete obstruction from in-stent thrombosis was detected by CT at 1 month after stent implantation (Figure 2). Catheter-directed thrombolysis was not performed, but antico- agulation therapy was resumed, but despite long-term anticoagulation therapy, recanalization was not achieved. Finally, we ceased the anticoagulation therapy at 28 months according to the patient's wishes. After cessation of anticoagulation therapy, exacerbation of lower limb swelling has not been observed.

\section{Long-Term Follow-up}

The mean follow-up after stent implantation was 79.9 \pm 29.8 months (range 28-117 months). During follow-up, 2 patients died of tongue cancer and postoperative ileus, respectively. No deaths because of venous thromboembolism occurred. We list the long-term outcomes of anticoagulation therapy in Table 3. At the time of the last follow-up examination, 7 patients had 


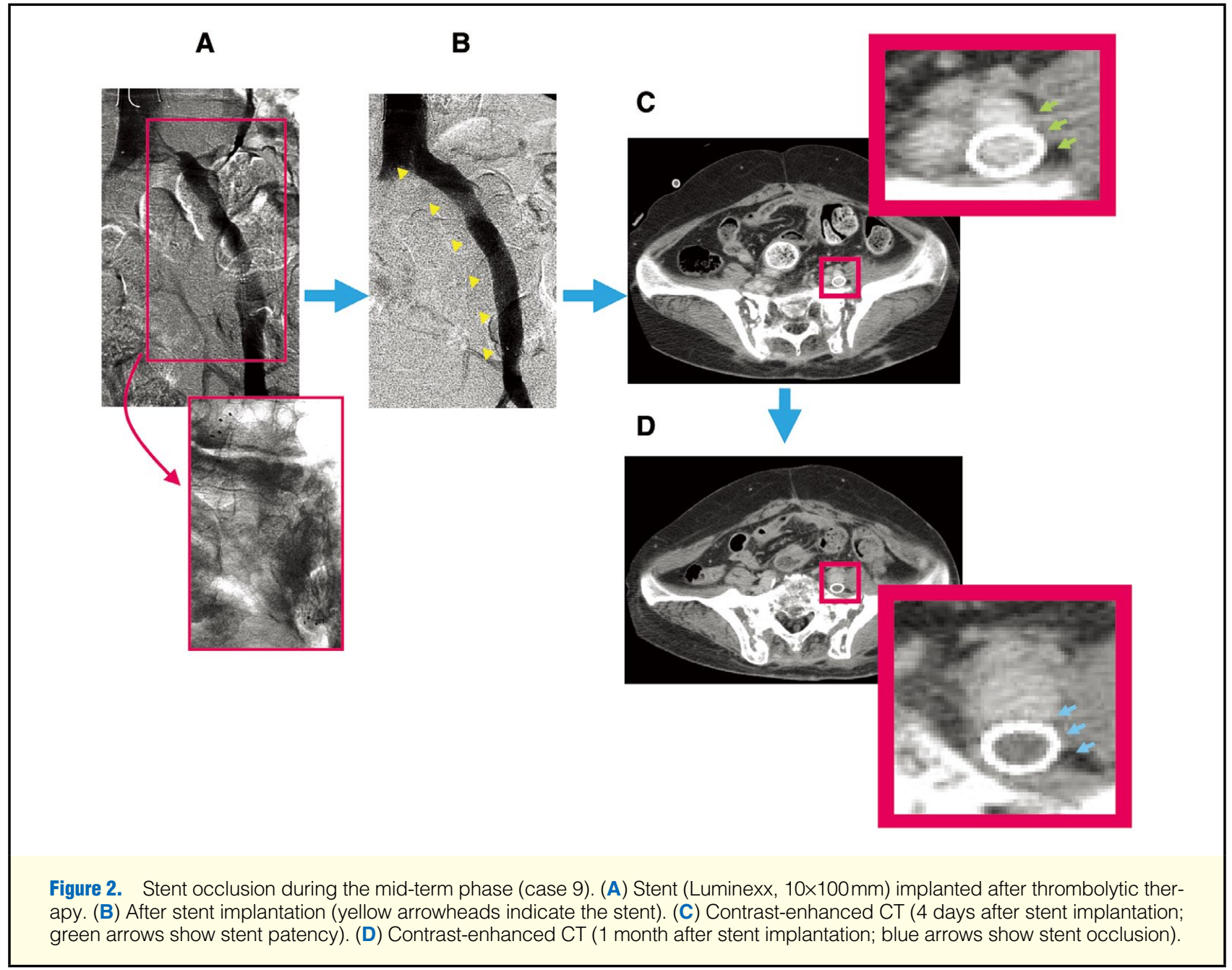

stopped taking anticoagulants, and 6 patients were continuing to receive anticoagulation therapy. The mean duration of anticoagulant therapy in the patients who ceased treatment was $42.0 \pm 24.1$ months. None of the surviving patients who had ceased anticoagulation therapy developed recurrent venous thromboembolism. Contrast-enhanced CT was performed to examine the long-term stent patency in 5 patients (including 2 patients who had discontinued anticoagulation therapy; mean duration of stent implantation: 79.6 \pm 31.2 months). Good stent patency was observed in all 5 patients, and none of the stents had fractured.

Only 1 patient had leg swelling according to the CEAP classification (C3), but post-thrombotic syndrome was not observed in any other patient (CEAP classification: $\mathrm{C} 0$ ).

\section{Discussion}

Venous stenosis can lead to blood flow stagnation and cause DVT. ${ }^{5}$ Also, the administration of anticoagulation therapy alone in patients with poor collateral vessels can lead to leg swelling, pain, and skin ulcers because of venous stenosis. ${ }^{6}$ Therefore, it is important to treat stenotic lesions in such patients.

In recent years, the use of catheter interventions for vascular disease has spread rapidly in conjunction with the development of catheter devices. In addition, catheter-directed throm- bolysis is being increasingly used to treat DVT and venous disease. ${ }^{7}$ Stent implantation for venous stenosis is a catheter intervention for venous disease and is considered to be an effective treatment for venous stagnation. In our hospital, venous stents are implanted in patients with venous stasis because of severe stenosis after complete thrombolysis. On the other hand, we exclude young subjects or with a rich collateral through the pelvic venous plexus.

All patients in the present series were suffering from left common iliac vein stenosis. The left common iliac vein is often compressed (iliac compression syndrome) because it runs behind the right iliac artery, and in some patients there is a pelvic venous spur in this region. As a result, the left leg is prone to venous stagnation and DVT. ${ }^{8}$

To treat the patients with DVT, we placed a sheath in the popliteal vein ipsilateral to the lesion and performed stent implantation. After stent implantation, stent expansion was confirmed by IVUS. The 6 patients who exhibited inadequate stent expansion were treated with additional low-pressure balloon dilatation. Vascular injury, bleeding, infection, and pulmonary embolism were absent as complications, but 1 patient suffered in-stent thrombosis just after stent implantation. In that patient, venous stenosis and a thrombus developed in the distal part of the lesion, probably because of in-stent thrombus formation. Catheter-directed thrombolysis was highly effective, but venous stenosis remained in the distal portion of the lesion. 
Blood flow stagnation was also observed at this site, and so an additional stent was implanted. After treatment, no recurrence developed during the chronic phase of the patient's condition.

Only 1 patient developed stent obstruction in the acute phase and that patient did not undergo balloon dilatation after stent implantation. Angiography performed just after stent implantation suggested that the stent might not have been large enough. Therefore, it was considered that blood flow stagnation led to the formation of a thrombus. The patient's blood flow was restored by catheter-directed thrombolysis, and no recurrence was observed.

IVC filters are often required in cases of acute DVT treated with a catheter intervention. ${ }^{9}$ In this study, we implanted retrievable IVC filters in all patients. After completion of the catheter intervention, the IVC filters can be retrieved. However, implantation of a permanent IVC filter increases the risk of recurrent DVT, ${ }^{10,11}$ so IVC filters should only be implanted during the catheter intervention. In this study, all of the IVC filters were successfully retrieved.

Of the 10 patients in whom we were able to assess stent patency during the mid-term follow-up phase, occlusion was only observed in 1 patient. After discharge, the latter patient decided to stop warfarin therapy (10 days after stenting). In all other cases in which anticoagulation was continued, the stents remained patent. According to the guideline, ${ }^{12}$ anticoagulation therapy for venous thromboembolism is necessary for at least 3 months. We maintain that a longer duration of anticoagulation is necessary for venous stents. However, there is no evidence for the duration of anticoagulation for the venous stent. Among our cases, 6 patients with no persistent risk factors of venous thromboembolism discontinued anticoagulation therapy after a mean of 42 months and none had a recurrence of DVT. Although a shorter duration may be adequate, further prospective studies are needed to confirm the optimal duration of anticoagulation therapy for venous stents.

Table 4 summarizes the findings of some previous reports on stent implantation for venous stenosis. ${ }^{13-22}$ All these studies report high patency rates during the acute and chronic phases. In most of them, chronic patency was assessed using venous ultrasound, but because the veins in the pelvis are difficult to observe on ultrasound, ${ }^{23}$ stent patency was inferred from assessments of peripheral blood flow. In contrast, we have high confidence in our results, as stent patency was assessed by angiography in the current study. In the present study, the acute phase patency rate was $92.3 \%$, and the mid-term patency rate was $90.0 \%$. Also, long-term stent patency was assessed by contrast-enhanced CT in 5 patients and in all of them the stents exhibited good patency, and there were no fractured stents. Thus, stent implantation is considered to be an appropriate treatment for venous stenosis.

\section{Conclusions}

In conclusion, venous stent implantation for iliac venous stenosis is associated with a high long-term patency rate and is an effective and safe therapy.

\section{References}

1. Hirsch AT, Haskal ZJ, Hertzer NR, Bakal CW, Creager MA, Halperin JL, et al. ACC/AHA 2005 Practice Guidelines for the management of patients with peripheral arterial disease (lower extremity, renal, mesenteric, and abdominal aortic): A collaborative report from the American Association for Vascular Surgery/Society for Vascular Surgery, Society for Cardiovascular Angiography and Interventions,
Society for Vascular Medicine and Biology, Society of Interventional Radiology, and the ACC/AHA Task Force on Practice Guidelines (Writing Committee to Develop Guidelines for the Management of Patients With Peripheral Arterial Disease): Endorsed by the American Association of Cardiovascular and Pulmonary Rehabilitation; National Heart, Lung, and Blood Institute; Society for Vascular Nursing; TransAtlantic Inter-Society Consensus; and Vascular Disease Foundation. Circulation 2006; 113: e463-e654.

2. Soga Y, Iida O, Kawasaki D, Yamauchi Y, Suzuki K, Hirano K, et al. Contemporary outcomes after endovascular treatment for aorto-iliac artery disease. Circ J 2012; 76: 2697-2704.

3. Tsuji A, Yamada N, Ota S, Ishikura K, Najamura M, Ito M. Early results of rheolytic thrombectomy in patients with proximal deep vein thrombosis. Circ J 2011; 75: 1742-1746.

4. Eklöf B, Rutherford RB, Bergan JJ, Carpentier PH, Gloviczki P, Kistner $\mathrm{RL}$, et al. Revision of the CEAP classification for chronic venous disorders: Consensus statement. J Vasc Surg 2004; 40: 1248-1252.

5. Hirsh J, Hoak J. Management of deep vein thrombosis and pulmonary embolism. Circulation 1996; 93: 2212-2245.

6. Raju S, Neglen P. High prevalence of nonthrombotic iliac vein lesions in chronic venous disease: A permissive role in pathogenicity. J Vasc Surg. 2006; 44: 136-143.

7. Yamada N, Ishikura K, Ota S, Tsuji A, Nakamura M, Ito M, et al. Pulse-spray pharmacomechanical thrombolysis for proximal deep vein thrombosis. Eur J Vasc Endovasc Surg 2006; 31: 204-211.

8. Ferris EJ, Lim WN, Smith PL, Casali R. May-Thurner syndrome. Radiology 1983; 147: 29-31.

9. El Sayed HF, Kougias P, Zhou W, Lin PH. Utility of retrievable vena cava filters and mechanical thrombectomy in the endovascular management of acute deep venous thrombosis. Vascular 2006; 14: 305-312.

10. Decousus H, Leizorovicz A, Parent F, Tardy B, Girard P, Laporte S, et al. A clinical trial of vena caval filters in the prevention of pulmonary embolism in patients with proximal deep-vein thrombosis: Prevention du Risque d'Embolie Pulmonaire par Interruption Cave Study Group. N Engl J Med 1998; 338: 409-415.

11. Ota S, Yamada N, Tsuji A, Ishikura K, Nakamura M, Ito M, et al. The Günther-tulip retrievable IVC filter: Clinical experience in 118 consecutive patients. Circ J 2008; 72: 287-292.

12. Guidelines for the Diagnosis, Treatment and Prevention of Pulmonary Thromboembolism and Deep Vein Thrombosis (JCS 2009). Circ J 2011; 75: 1258-1281.

13. Binkert CA, Schoch E, Stuckmann G, Largiarder J, Wigger P, Schkoepke W, et al. Treatment of pelvic venous spur (May-Thurner syndrome) with self-expanding metallic endoprostheses. Cardiovasc Intervent Radiol 1998; 21: 22-26.

14. Patel NH, Stookey KR, Ketcham DB, Cragg AH. Endovascular management of acute extensive iliofemoral deep venous thrombosis caused by May-Thurner syndrome. J Vasc Interv Radiol 2000; 11: $1297-1302$

15. O'Sullivan GJ, Semba CP, Bittner CA, Kee ST, Razaki MK, Sze DY, et al. Endovascular management of iliac vein compression (MayThurner) syndrome. J Vasc Interv Radiol 2000; 11: 823-836.

16. Heijmen RH, Bollen TL, Duyndam DA, Overtoom TT, Van Den Berg JC, Moll FL, et al. Endovascular venous stenting in May-Thurner syndrome. J Cardiovasc Surg 2001; 42: 83-87.

17. Hurst DR, Forauer AR, Bloom JR, Greenfield LJ, Wakefield TW, Williams DM. Diagnosis and endovascular treatment of iliocaval compression syndrome. J Vasc Surg 2001; 34: 106-113.

18. Lamont JP, Pearl GJ, Patetsios P, Warner MT, Gable DR, Garrett W, et al. Prospective evaluation of endoluminal venous stents in the treatment of the May-Thurner syndrome. Ann Vasc Surg 2002; 16: 61-64.

19. Kwak HS, Han YM, Lee YS, Jin GY, Chung GH. Stents in common iliac vein obstruction with acute ipsilateral deep venous thrombosis: Early and late results. J Vasc Interv Radiol 2005; 16: 815-822.

20. Kim JY, Choi D, Guk Ko Y, Park S, Jang Y, Lee do Y. Percutaneous treatment of deep vein thrombosis in May-Thurner syndrome. Cardiovasc Intervent Radiol 2006; 29: 571-575.

21. Hartung O, Benmiloud F, Barthelemy P, Dubuc M, Boufi M, Alimi YS. Late results of surgical venous thrombectomy with iliocaval stenting. J Vasc Surg 2008; 47: 381-387.

22. Funatsu A, Nakamura S. Stent implantation for iliac compression syndrome with acute deep venous thrombosis. Jpn J Phlebol 2012; 23: $283-293$.

23. Oda S, Utsunomiya $D$, Funama $Y$, Shimonobo $T$, Namimoto $T$, Itatani $\mathrm{R}$, et al. Evaluation of deep vein thrombosis with reduced radiation and contrast material dose at computed tomography venography: Clinical application of a combined iterative reconstruction and lowtube voltage technique. Circ J 2012; 76: 2614-2622. 